\title{
A STUDY OF DRUG UTILIZATION PATTERN OF THE GERIATRIC PATIENTS IN THE DEPARTMENT OF GERIATRIC MEDICINE IN A TERTIARY CARE HOSPITAL IN ASSAM, INDIA
}

\author{
LAKHIMI BORAH, DIPTIMAYEE DEVI, PRASANJIT K DEBNATH*, DIBYAJYOTI DEKA
}

Department of Pharmacology, Gauhati Medical College, Guwahati, Assam, India. Email: pkd281283@gmail.com

Received: 18 August 2016, Revised and Accepted: 26 October 2016

ABSTRACT

Objective: To investigate the drug utilization pattern and the prevalence of potentially inappropriate medications (PIMs) using updated AGS Beers Criteria 2012 among the elderly patients who attended the geriatric outpatient departments as well as admitted indoor patients in a Tertiary Care Hospital at Guwahati, Assam, India.

Methods: A hospital-based prospective, observational and cross sectional study, involving patients aged 65 years and above was planned and conducted over a period of 6-months from January 2016 to June 2016. Patients were visited daily, interviewed and case records were collected. Data were analyzed using Microsoft Office Excel Sheets.

Results: A total of 150 patients aged 65 years and above were analyzed. 97 patients (65\%) were males and 53 (35\%) were females. Majority of the patients ( 61 numbers, $41 \%$ ) belonged to the age group of 65-70 years, and least were in the age group of 86-90 years (13 numbers, $9 \%$ ). Prescription of five or more medications (polypharmacy) was observed in 117 (78\%) patients. Majority of the patients presented with diseases of cardiovascular system (25.7\%). Using the World Health Organization drug use indicators, the average number of drugs per prescription was found to be 5.6. The percentage of drugs prescribed by generic name was $86 \%$. The percentage of encounters in which antibiotics were prescribed was $61 \%$. Injection was prescribed was $65 \%$ cases and the percentage of drugs prescribed from the National List of Essential Medicines of India was $96 \% .43$ patients received PIMs from Beers list; majority were belonging to Category 1 . Spironolactone was most commonly prescribed PIM.

Conclusion: Irrational prescribing practices and polypharmacy were detected in our study. Prescribers should be educated about the rational use of drugs and Beers Criteria for elderly.

Keywords: Beers Criteria, World Health Organization prescribing indicators, Potentially inappropriate medications, Elderly patients, Polypharmacy. (c) 2017 The Authors. Published by Innovare Academic Sciences Pvt Ltd. This is an open access article under the CC BY license (http://creativecommons. org/licenses/by/4. 0/) DOI: http://dx.doi.org/10.22159/ajpcr.2017.v10i2.14762

\section{INTRODUCTION}

Drug utilization studies are exploratory tools to ascertain the role of drugs in the society. Geriatric medicine is the branch of gerontology which deals with clinical or medical aspect of gerontology [1]. There has been a steady increase in the number of elderly people, defined as those over 65 years of age. Several conditions are likely to be present [2]. Drug utilization research has been defined by the World Health Organization (WHO) in 1977 as study of marketing, distribution, prescription, and use of drugs in society, with special emphasis on the resulting medical, social, and economic consequences [3].

Considering the physiological changes that occur with aging and its impact on the pharmacokinetics and pharmacodynamics of drugs, it is essential to monitor drug effects, especially adverse drug reactions (ADRs) and drug interactions, vis-a-vis clinical outcome in geriatric patients [4]. The elderly population is increasing rapidly worldwide. Their growth rate $(1.9 \%)$ is higher than general population $(1.2 \%)$ [5]. At present, India is the third country after China and USA with large elderly population in the world. As per the 1991 census, the population of the elderly in India was 57 million as compared with 20 million in 1951.There has been a sharp increase in the number of elderly persons between 1991 and 2001 and it has been projected that by the year 2050, the number of elderly people would rise to about 324 million [6]. Elderly persons are our most medicated group of patients and are prescribed the highest proportion of medications. Pharmacotherapy is single most important intervention for care of the majority of elderly patients [7]. Their healthcare need differs from younger people. Though elderly are reported to be responsible for half the total drug usage, $<5 \%$ of randomized control trials have been designed for them [8].

Physiological and pharmacological variations in elderly population include decreased total body mass, blood flow to various organs, immunity, and nervous functions; down or up regulation of various receptors; and disturbance in first-pass metabolism, bioavailability, metabolism, and excretion $[9,10]$. The presence of comorbidities in elderly people requires use of multiple medications which increase the irrational prescription, use of inappropriate medications, noncompliance, economic burden, ADRs, and drug interactions [11]

Drug prescribing for older patients offers special challenges. As compared to the younger individuals, older people take about 3 times more medications because of the increased incidence of chronic problems [12]. The overall incidence of ADR is 2-3 times higher and most of them are potentially avoidable in elderly patients [13]

Assessment of drug use patterns with the WHO drug use indicators is becoming increasingly necessary to promote rational drug use in developing countries $[14,15]$. Rational use of drugs can be analyzed using WHO drug use indicators. Among the elderly, potentially inappropriate medications (PIMs) have been found to be a common cause of morbidity and mortality [16]. Beers Criteria, which was initially released in 1997 and updated in 2002 and 2012, is an important criteria for safe use of medicines among the elderly [17-19]. The Beers Criteria consist of medications to be avoided in the elderly irrespective of the patient's diagnosis, and those that should be avoided when taking a particular diagnosis into account [18]. PIMs, according 
to Beers Criteria, are divided into three categories, such as Category 1, Category 2, and Category 3. Beers Criteria have become established as a standardized tool for pharmacological research especially for elderly age group [19].

\section{METHODS}

\section{Study design}

A hospital-based prospective, observational and cross sectional study, involving patients aged 65 years and above was planned and conducted over a period of 6-months from January 2016 to June 2016 in Gauhati Medical College and Hospital, Guwahati, India. Institutional ethical committee approval was obtained before commencement of the study procedure.

\section{Sample selection}

Patients of either gender aged 65 years and above, who attended the geriatric outpatient departments as well as admitted indoor patients, were included in the study.

\section{Criteria for inclusion of participant's}

Patients of either gender who had completed 65 years of age on December $31^{\text {st }}, 2015$, or earlier and who were admitted to the ward or visited outpatient department (OPD) of Geriatric Medicine Department and who give informed consent were included in the study.

\section{Exclusion criteria}

Patients who were unwilling to participate in the study, seriously ill requiring intensive care unit admissions or on ventilators and those who were mentally unstable were excluded.

Patients were visited daily, interviewed and case records were checked. The information obtained from them was transferred into a pre-structured case record form.

\section{Data analysis}

Data were collected in a structured pro forma, which included age, sex, department, diagnosis, OPD registration number, indoor registration number, hospital number and complete prescription including the prescribed drugs and their dosages. These data were analyzed under the headings such as, demographic details, polypharmacy, prevalence of disease conditions, comorbid illness, category of drugs, most frequently prescribed drugs and fixed-dose combination.

WHO prescribing indicators were assessed such as [20]:

I. Average number of the drugs per prescription

II. Percentage of the drugs prescribed by generic name

III. Percentage of encounters in which an antibiotic was prescribed

IV. Percentage of encounters with an injection was prescribed

V. Percentage of the drugs prescribed from an essential drug list.

For the potentially inappropriate prescription among the elderly, American Geriatric Society updated Beers Criteria 2012 was used and analyzed. These are as following:

- Category 1: PIM and classes to avoid in older adults

- Category 2: Category 1 with certain diseases and syndrome that the drugs listed can exacerbate

- Category 3: Drugs used with caution in older adults [19]

\section{Statistical analysis}

The data were subjected to analysis using Microsoft Excel. Drugs were classified according to the WHO-ATC classification and verified by WHO Essential Medicine List as well as National List of Essential Medicines (NLEM) 2011

\section{RESULTS}

A total of 150 patients who visited geriatric OPD as well as admitted in geriatric ward were included. Their socio-demographic profile was analyzed as shown in Table 1.
As shown in Table 1, 97 patients (65\%) were males and 53 (35\%) were females. The male to female ratio was 1:0.55. Most of the patients (82 numbers, 55\%) were illiterate, and most of them (89 numbers, 59\%) belonged to lower middle-class family.

As shown in Fig. 1, majority of the patients (61 numbers, 41\%) belonged to the age group of 65-70 years and least were in the age group of 8690 years (13 numbers, $9 \%$ ).

A total of 834 drugs were prescribed for the patients. 5 and 7 drugs per prescription were given to highest numbers of patients (36 number, $24 \%$ of patients each) and least were 3 drugs per prescription (6 patients, 4\%) (Fig. 2).

A total of 834 drug products were prescribed. Thus, the average number of drugs per prescription or mean was 5.6 with a range between 3 and 9 . The total number of drugs prescribed by generic name was 721 (86\%). An antibiotic was prescribed in 92 patient encounters (61\%), and an injection was prescribed in 98 encounters (65\%) (Table 2). Almost all drugs prescribed $(n=804,96 \%)$ were on the NLEM of India.

The majority of the patients presented with diseases of cardiovascular system (25.7\%), followed by respiratory system (14.1\%), musculoskeletal conditions (13\%), and gastrointestinal tract (GIT) diseases $(11.8 \%)$. The rest of the cases were related to other organ systems as given in Fig. 3

The various groups of drugs prescribed to the elderly patients were shown in Fig. 4. Drugs acting on cardiovascular system were prescribed most (22.4\%), followed by drugs acting on GIT $(20.3 \%)$ and antimicrobials (15.7\%). Least prescribed were drugs effecting blood and blood formation (5.4\%) and miscellaneous (4.8\%).

Based on 2012 updated Beers Criteria by the American Geriatric Society, we found in our study, out of 150 patients, 43 patients $(28.7 \%)$ received

Table 1: Sociodemographic parameters

\begin{tabular}{ll}
\hline Sociodemographic parameters & Characteristic groups (\%) \\
\hline Age & $97(65)$ \\
Male & $53(35)$ \\
Female & \\
Literacy & $82(55)$ \\
Illiterate & $26(17)$ \\
Up to $10^{\text {th }}$ & $19(13)$ \\
Up to $12^{\text {th }}$ & $15(10)$ \\
Graduate & $8(5)$ \\
Postgraduate & \\
Socio-economic condition & $89(59)$ \\
Lower middle class & $46(31)$ \\
Middle class & $15(10)$ \\
Upper middle class &
\end{tabular}

Table 2: Drug use pattern using WHO prescribing indicators [15

\begin{tabular}{lll}
\hline Prescribing indicators & $\begin{array}{l}\text { Total drugs/ } \\
\text { prescriptions }\end{array}$ & $\begin{array}{l}\text { Average/ } \\
\text { percent }\end{array}$ \\
\hline $\begin{array}{l}\text { Average number of drugs per } \\
\text { encounter }\end{array}$ & 834 & 5.6 \\
$\begin{array}{l}\text { Percentage of encounter with } \\
\text { antibiotics }\end{array}$ & 92 & 61 \\
$\begin{array}{l}\text { Percentage of encounters with } \\
\text { injection }\end{array}$ & 98 & 65 \\
$\begin{array}{l}\text { Percentage of drugs prescribed } \\
\text { by generic }\end{array}$ & 721 & 86 \\
$\begin{array}{l}\text { Percentage of drugs from } \\
\text { essential drug list [18] }\end{array}$ & 804 & 96 \\
\hline
\end{tabular}

WHO: World Health Organization 
at least one drug which was PIM from Beers list. Out of 834 drugs, a total of 67 PIMs were prescribed in all with 13 responsible medications identified. Out of the 43 patients, 26 patients (60.46\%) were prescribed to have a single drug of PIMs from Beers list. 10 patients $(23.25 \%)$ were prescribed to have two different PIMs, and 7 patients $(16.28 \%)$ were prescribed to have three different PIMs from Beers list, which is shown in Fig. 5. Medications to be avoided in elderly patients (Category 1) being the most common category of inappropriate use, which is shown in Table 3. Spironolactone was prescribed PIMs in 9 cases, followed by diclofenac and chlorzoxazone in 8 cases. Least prescribed PIMs were chlorpheniramine and alprazolam in 2 and 1 cases respectively. Under Category 3, aspirin was the only drug which was prescribed to 2 patients.

\section{DISCUSSION}

In this study, records of 150 patients were analyzed out of which $65 \%$ were males and $35 \%$ females, which is similar to other studies conducted in India $[8,16,21]$. The majority of the patients $(41 \%)$ belonged to the age group of 65-70 years, and least were in the age group of $86-90$ years (9\%), which is similar to previous studies on

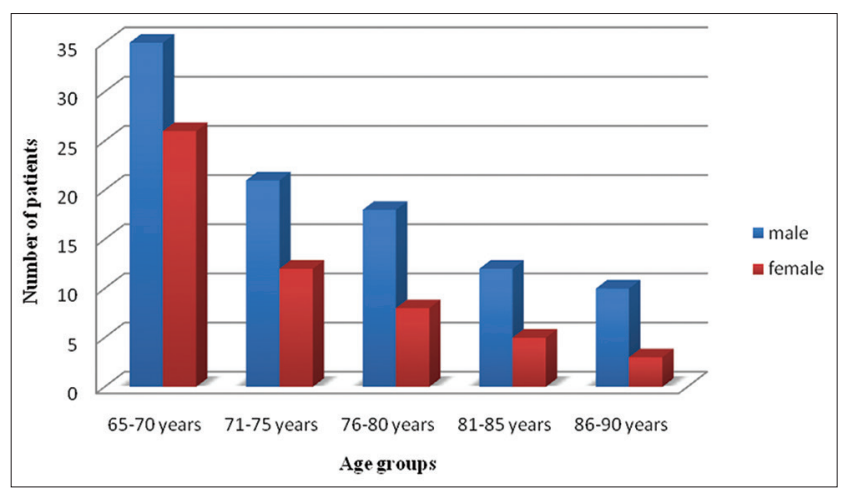

Fig. 1: Age and gender distribution of the patients

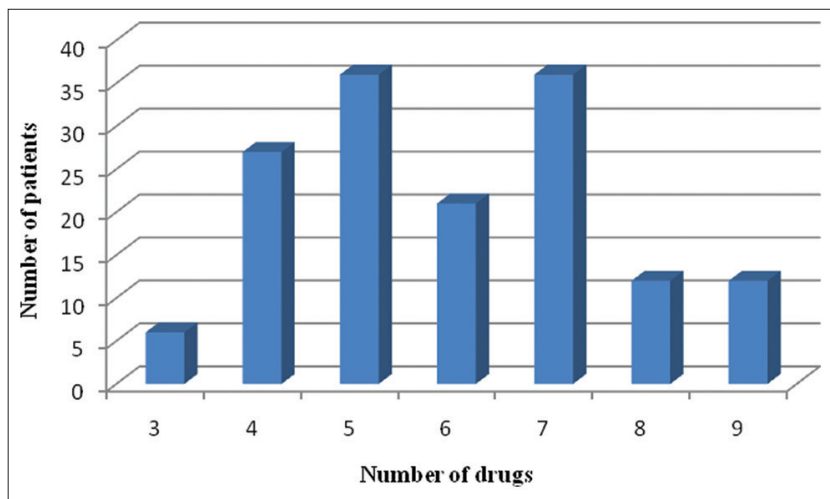

Fig. 2: Number of drugs per prescription

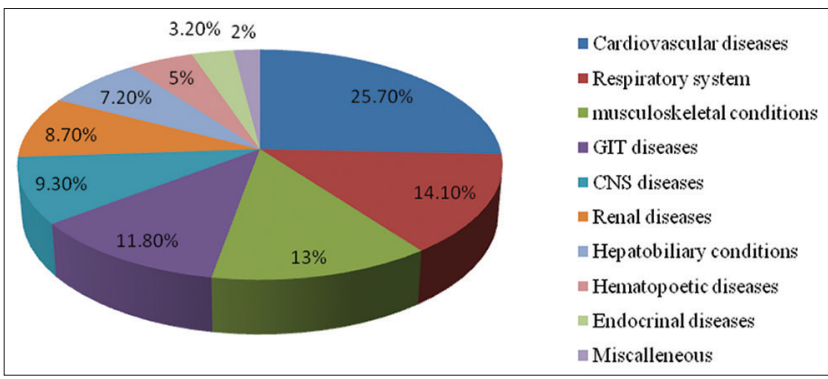

Fig. 3: Disease prevalence among elderly geriatric patients conducted in India [16]. However, in a similar study conducted in South India showed more female population [22].

Nearly, $55 \%$ of patients were illiterate, and only $5 \%$ had post-graduate degree. 59\% belonged to lower middle class, and only $10 \%$ belonged to upper middle class compared to a similar study by Shah et al. [21] where $65.5 \%$ of the patients had basic education and $86.5 \%$ were from the lower and middle socioeconomic status.

Analysis of prescriptions using WHO drug use indicators showed that the average number of drugs per prescription was 5.6 which is less than a similar study on geriatric population conducted in India, where the average was 7.3. Maximum 9 drugs were given to a patient, whereas, up to 27 drugs were prescribed in similar study in India [21]. Prescription of five or more medications (polypharmacy) was observed in 117 (78\%) patients in our study. In contrast, polypharmacy was observed only in $16.5 \%$ patients in a study conducted in Pondicherry [16].

Concerns about polypharmacy include increased ADRs, drug interactions, prescribing cascade and higher costs [23]. Polypharmacy is often associated with a decreased quality of life, decreased mobility and cognition [24].

The percentage of drugs prescribed by generic name was $86 \%$, which is almost satisfactory, compared to standard derived or ideal (100\%) [25]. Similar studies conducted at Karnataka [22] showed it to be $70 \%$ whereas in a study on geriatric population conducted in Pondicherry [16] found it to be $21.31 \%$, which is much less than ours.

The percentage of encounters in which antibiotics were prescribed was $61 \%$, which is very high compared to the standard (20.0-26.8\%) derived to be ideal [25]. In a similar study conducted in India [16], it was found to be $23.5 \%$, which is acceptable and much lower than our findings. Injudicious use of antibiotics must be discouraged to prevent the emergence of antibiotic resistance.

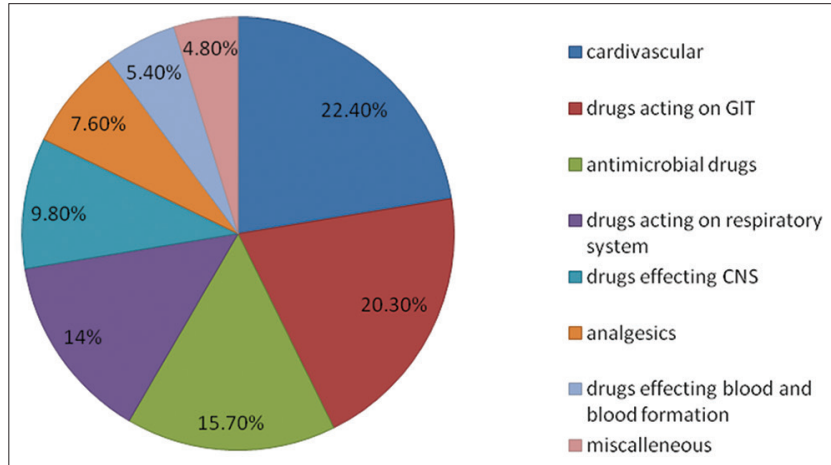

Fig. 4: Various groups of drugs prescribed

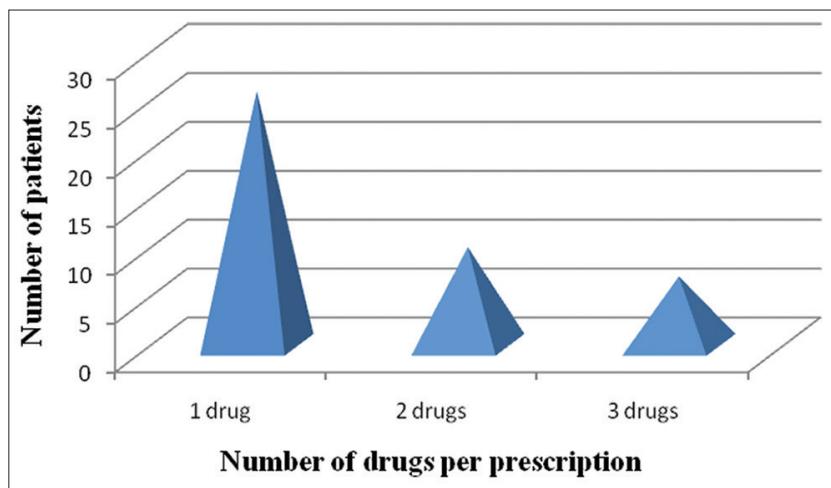

Fig. 5: Frequency of potentially inappropriate medications prescribed from the list of updated AGS Beers Criteria 
Table 3: List of PIMs used in elderly based on AGS updated Beers Criteria

\begin{tabular}{llll}
\hline Category & Name of drugs & Total=67 & Frequency (\%) \\
\hline 1. & Medications and class to & & \\
& avoid in older adults & & \\
& Spironolactone & 9 & 13.43 \\
Diclofenac & 8 & 11.94 \\
Chlorzoxazone & 8 & 11.94 \\
Dicyclomine & 7 & 10.45 \\
Cyproheptadine & 6 & 8.95 \\
Clinidium-chlordiazepoxide & 6 & 8.95 \\
& Digoxin & 5 & 7.46 \\
& Indomethacin & 5 & 7.46 \\
Ibuprofen & 4 & 5.97 \\
& Sliding scale insulin & 4 & 5.97 \\
& Chlorpheniramine & 2 & 2.98 \\
Alprazolam & 1 & 1.4 \\
To be avoided with specific & Nil & \\
2. & comorbidity & & \\
3. & Medications to be used & & \\
& with caution in older adults & & 2.98 \\
\hline
\end{tabular}

PIM: Potentially inappropriate medications

The percentage of encounters in which an injection was prescribed was $65 \%$, which is much higher than the standard (13.4-24.1\%) derived to be ideal [25]. This may be due to psychological advantage of injections on patients and treating doctors. Whereas, in a similar study conducted in India [22], it was $26.33 \%$, and is within acceptable limits.

The percentage of drugs prescribed from the NLEM of India was $96 \%$, which is close to the standard (100\%) derived as ideal [25]. In similar studies conducted in India $[16,21]$, it was much less than ours.

The majority of the patients presented with diseases of cardiovascular system (25.7\%), followed by respiratory system (14.1\%), musculoskeletal conditions (13\%), and GIT diseases $(11.8 \%)$ whereas in another study [16] in India, cardiovascular, musculoskeletal, and endocrine systems were involved in decreasing order.

According to AGS Updated Beers Criteria 2012 for PIM use in elderly, our study shows almost $28.7 \%$ of elderly patient had encountered with at least one drug of PIMs. Although it is higher than similar study conducted in India (18.34\%) [16], but it is similar to other studies conducted in the USA $(27.5 \%)$ and Iran $(27.6 \%)$ [26,27]. In this study, $8.04 \%$ of total drugs prescribed were PIMs, which is similar (7.75\%) to another study conducted in India [16].

In our study, 12 different drugs were prescribed to these patients from Category 1, which represents the category of drugs to be avoided in elderly. Spironolactone was most commonly prescribed PIM followed by diclofenac, chlorzoxazone, and dicyclomine whereas in another study conducted in India [8] diclofenac, spironolactone, chlorzoxazone and digoxin were prescribed in decreasing order of frequency.

\section{CONCLUSION}

Our study unveils information to the prescribers in the prescribing practice of drug utilization in elderly patients to encourage the rational use of drugs. Irrational prescribing and polypharmacy were found to be highly prevalent among elderly in our hospital. Comprehensive method and diagnosis data to assess drug utilization study and PIMs prescribing to elderly patients applying the recent updated Beers Criteria were used. PIMs prescribing were a major point of concern. The prescribers should be motivated about WHO prescribing indicators and AGS Beers Criteria in clinical practice in geriatric population. The present study has been an eye opener on the geriatric population and would inspire others to do further research in this area.

\section{REFERENCES}

1. Shahet SN. API Textbook of Medicine. $8^{\text {th }}$ ed., Vol. 2. Washington, DC: Munjal; 2003. p. 1578-80.

2. Upadhyay J, Joshi Y. Observation of drug utilization pattern and prevalence of diseases in elderly patients through home medication review. Asian J Pharm Clin Res 2011;4(1):143-5.

3. World Health Organization. Introduction to Drug Utilization Research. Geneva: World Health Organization; 2003

4. Dipiro JT, Talbert RL, Yee GC, Matzke GR, Wells BG, Posey LM, editors. Pharmacotherapy: A Pathophysiologic Approach. $7^{\text {th }}$ ed. New York: McGraw Hill; 2008. p. 57-66.

5. Chanana HB, Talwar PP. Aging in India: Its socioeconomic and health implications. Asia Pac Popul J 1987;2(3):23-38.

6. Age Care Statistics. Available from: http://www.helpageindia.com.

7. Reddy P, Gosavi D, Varma SK. An overview of geriatric pharmacology. Asian J Pharm Clin Res 2012;5(4):25-9.

8. Zaveri HG, Mansuri SM, Patel VJ. Use of potentially inappropriate medicines in elderly: A prospective study in medicine out-patient department of a tertiary care teaching hospital. Indian J Pharmacol 2010;42(2):95-8

9. Klotz U. Pharmacokinetics and drug metabolism in the elderly. Drug Metab Rev 2009;41(2):67-76.

10. Corsonello A, Pedone C, Incalzi RA. Age-related pharmacokinetic and pharmacodynamic changes and related risk of adverse drug reactions. Curr Med Chem 2010;17(6):571-84

11. Gorzoni ML, Fabbri RM, Pires SL. Potentially inappropriate medications in elderly. Rev Assoc Med Bras 2012;58(4):442-6.

12. Rochon PA, Gurwitz JH. Drug therapy. Lancet 1995;346(8966):32-6.

13. Helldén A, Bergman U, von Euler M, Hentschke M, Odar-Cederlöf I, Ohlén G. Adverse drug reactions and impaired renal function in elderly patients admitted to the emergency department: A retrospective study. Drugs Aging 2009;26(7):595-606.

14. Hogerzeil HV, Bimo, Ross-Degnan D, Laing RO, Ofori-Adjei D, Santoso B, et al. Field tests for rational drug use in twelve developing countries. Lancet 1993;342(8884):1408-10.

15. WHO. How to Investigate Drug Use in Health Facilities: Selected Drug Use Indicators, WHO/DAP/93.1. Geneva: WHO; 1993

16. Kanagasanthosh K, Topno I, Aravindkumar B. Prevalence of potentially inappropriate medication use and drug utilization pattern in elderly patients: A prospective study from a tertiary care hospital. Int J Res Med Sci 2015;3(8):2062-72.

17. Beers $\mathrm{MH}$. Explicit criteria for determining potentially inappropriate medication use by the elderly. An update. Arch Intern Med 1997;157(14):1531-6

18. Fick DM, Cooper JW, Wade WE, Waller JL, Maclean JR, Beers MH. Updating the Beers Criteria for potentially inappropriate medication use in older adults: Results of a US consensus panel of experts. Arch Intern Med 2003;163(22):2716-24.

19. American Geriatrics Society 2012 Beers Criteria Update Expert Panel. American Geriatrics Society updated Beers Criteria for potentially inappropriate medication use in older adults. J Am Geriatr Soc 2012;60(4):616-31.

20. Available from: http://www.pharmaceuticals.gov.in/nlem.pdf.

21. Shah RB, Gajjar BM, Desai SV. Drug utilization pattern among geriatric patients assessed with the anatomical therapeutic chemical classification defined daily dose system in a rural tertiary care teaching hospital. Int J Nutr Pharmacol Neurol Dis 2012;2(3):258-65.

22. Nayaka SR, Rajeshwari B, Venkatadri TV. Drug utilization pattern in geriatric inpatients of medicine department in a Tertiary Care Teaching Hospital. Int J Basic Clin Pharmacol 2015;3(4):568-73.

23. Haider SI, Johnell K, Weitoft GR, Thorslund M, Fastbom J. The influence of educational level on polypharmacy and inappropriate drug use: A register-based study of more than 600,000 older people. J Am Geriatr Soc 2009;57(1):62-9.

24. Polypharmacy in Elderly Patients (PDF). Available from: http://www. vumc.nl. [Last retrieved on 2015 Jan 16].

25. Isah AO, Ross-Degnan D, Quick J, Laing R, Mabadeje AF. The development of standard values for the WHO drug use prescribing indicators. ICUM/EDM/WHO. Available from: http://www.archives. who.int/prduc2004/rducd/ICIUM Posters/1a2 txt.htm

26. Vlahovic-Palcevski V, Bergman U. Quality of prescribing for the elderly in Croatia-computerized pharmacy data can be used to screen 
for potentially inappropriate prescribing. Eur J Clin Pharmacol 2004;60(3):217-20.

27. Gallagher P, O'Mahony D. STOPP (Screening Tool of Older Persons' potentially inappropriate Prescriptions): Application to acutely ill elderly patients and comparison with Beers' Criteria. Age Ageing 2008;37(6):673-9 